\title{
Cheating the Ferryman: A New Paradigm of Existence?
}

\author{
Anthony A. Peake \\ Nuffield Hospitals, Harrogate, North Yorkshire, \\ England
}

"Life reduces itself to a series of epileptic attacks, preceded and followed by a blank."

Edmond de Goncourt (cited in Lombroso, 1891, p. 342)

\begin{abstract}
Survival after death of the body is arguably the most fundamental question facing sentient beings. I present a rationalistic argument for what occurs subjectively at the moment of death, using insights from quantum physics, neurology, perceptual science, psychiatry, and Gnosticism. At the point of death, three events are brought about by neurotransmitters flooding the temporal lobes. First, the dying person "falls out of time" as the speed by which stimuli are processed by the brain is altered. Second, the person's consciousness splits into two independent entities, the Eidolon ("I") and the Daemon ("higher self"). Third, the brain starts a "real time" recreation of the subject's life projected into consciousness of the Eidolon as a reality indistinguishable from the real thing. The Eidolon lives its life again as if it was the first time, but now with a higher self (Daemon) taking the role of a guide. This second life runs in an alternative universe within the consciousness of the perceiver and takes place in the microsecond before the perceiver is seen to die in the universe of any observers. In the observers' universe, the perceiver dies; but for the dying person, time expands to make that last microsecond last a lifetime. At the end of the second "lifetime," the same process occurs again in an even smaller segment of time, a literal version of the "Eternal Return."
\end{abstract}

$K E Y$ WORDS: quantum mechanics; many worlds interpretation; life review; schizophrenia; temporal lobe epilepsy; déjà vu.

Anthony A. Peake is Divisional Human Resources Manager for North of England and Scotland for Nuffield Hospitals in the United Kingdom. He holds a joint honors degree in sociology and history from the University of Warwick and a postgraduate diploma from the London School of Economics. Reprint requests should be addressed to Mr. Peake at Harrogate, North Yorkshire, UK; e-mail: tonyferryman@aol.com. 
According to ancient Greek myth, the first challenge confronting the recently dead was the crossing of the River Styx. At the riverbank they were met by a ferryman who would, for a payment, take them across to the opposite side, the realm of the dead known as Hades. This being, known as Charon, probably expected to make a fairly good living from the millions of obuli that he would receive. This article contends that Charon has been, for all times past and future, sitting disconsolately awaiting his first customer. Hades on the far bank will remain empty of souls, the screeches of the frustrated harpies echoing across the literally soulless landscape. Charon has been cheated by a trick of subjective temporal perception that ensures that no soul ever arrives at the riverbank, because personal death is an illusion.

To facilitate understanding of how I come to such a conclusion, I need to review the implications for the nature of matter of the latest theories of quantum physics and the relationship of such theories to the mechanism of human consciousness. Taken in isolation, these theories are fascinating and challenging ideas. However, they are rarely placed in the context of modern neurology, perceptual studies, and the evidence for human psychic duality. Central to the "Ferryman Thesis" is that all these seemingly unrelated areas of inquiry need to be brought together and the information reviewed in the light of what we know about near-death experiences (NDEs).

However, in order to appreciate the role of quantum physics and neurology within NDEs, we need to investigate the role of the phenomenon's "forgotten character." Like all classic mystery stories, the NDE plot line has its own intriguing stranger, a character whose motivations and reason for existence become clear only when the mystery is unraveled. This entity has a crucial role to play in the whole experience and yet has been curiously overlooked by many researchers. This has been an important oversight, because the entity often called the "being of light" may hold the key to the whole mystery of NDEs.

\section{The Daemon and the Eidolon}

In many classic NDE reports, the "being of light" appears at the point of death, guides the dying persons through such other elements as the life review, and is usually responsible for announcing that these persons need to return, as "it is not their time." This being manifests in many ways, usually in a form that is psychologically comforting to the dying person. However, in its classic form the being is simply a presence that communicates verbally or telepathically. 
To some researchers, this entity represents a projection from the subconscious of the dying person (Gabbard and Twemlow, 1984; Serdahely, 1987). This is evidenced from the seemingly culturally biased nature of its manifestation. To believers in the afterlife, it is what it seems to be: a relative, an angel, or even God Himself. However, I am of the opinion that this entity is the single most intriguing element of the phenomenon, because it may be proof of another long-held belief, the belief that all human beings consist of not one but two mutually independent consciousnesses (Novak, 1997, 2002, 2003).

This idea is culturally and historically almost universal. The ancient Chinese called these two independent consciousnesses hun and p'o, the ancient Egyptians the $k a$ and the $b a$, and the ancient Greeks the Daemon and the Eidolon. In each case, the two entities shared their senses and perceptions of the external world but interpreted those perceptions with regard to their own history, knowledge, and personality. For the Greeks, the relationship was an unequal one. The higher self, the Daemon, acted as a form of guardian angel over its lower self, the Eidolon. The Stoic philosopher Epictetus wrote:

God has placed at every man's side a guardian, the Daemon of each man, who is charged to watch over him; a Daemon that cannot sleep, nor be deceived. To what greater and more watchful guardian could He have entrusted each of us? So, when you have shut the doors, and made darkness in the house, remember, never to say that you are alone; for you are not alone. But God is there, and your Daemon is there (Epictetus, 1998/2 ${ }^{\text {nd }}$ century, 14:11)

The belief was that the Daemon had foreknowledge of future circumstances and events and as such could warn its Eidolon of the dangers. It was as if in some way the Daemon had already lived the life of its Eidolon.

However, the Daemon and Eidolon are more than cultural or theological beliefs. There is compelling evidence from both physiological and psychological experimentation that we all have a duality of consciousness. The human brain has two hemispheres, joined together by what is called the corpus callosum. For many years, surgeons had speculated as to what would happen to personality and consciousness if the callosum were cut and the subject survived.

In the 1960s, surgical techniques had progressed to the extent that such an operation could be attempted on human beings. Neurosurgeons Philip Vogel and Joseph Bogen concluded that certain epileptic patients would gain from such surgery and suffer no serious mental loss. Between 1962 and 1968 they performed nine such operations. 
Generally the effects of the operation were beneficial. All of the patients showed some short-term memory loss, problems of orientation, and mental fatigue immediately after the operation, and some of them were unable to speak for two months after the operation. But in all cases there was gradual recovery. Bogen and psychologist Michael Gazzaniga set up a series of tests to discover what changes had actually taken place in these patients. These tests were forever to change our understanding of how the human mind works. In short, they unknowingly confirmed the existence of the Daemon. The senior researcher behind the experiments, Roger Sperry, made the following observation:

In our "split-brain" studies of the past two decades ..., the surgically separated hemispheres of animals and man have been shown to perceive, learn, and remember independently, each hemisphere evidently cut off from the conscious experience of the other. In man the language-dominant hemisphere further reports verbally that it is not consciously aware of the concomitant or immediately preceding mental performances of the disconnected partner hemisphere. These test performances of which the speaking hemisphere remains unaware obviously involve perception, comprehension, and in some cases non-verbal memory, reasoning, and concept formation of different kinds depending on the nature of the test task. In these and many other respects, the split-brain animal and man behave as if each of the separated hemispheres had a mind of its own. (Sperry, 1976 , p. 170)

This analysis was strongly reinforced by the work of psychologist Roland Puccetti, who came to the conclusion that even without commissurotomy there are always two independent centers of consciousness in the human brain. He appealed to the cases where a complete hemisphere was removed. In this event, and whichever hemisphere was left, there remained a person. He argued that if people were unitary, then these operations or circumstances would leave only half a person. Puccetti concluded that the only way he could explain the completeness of the remaining person was by supposing that before the operation there was not a unitary person. He wrote:

He or she was a compound of two persons who functioned in concert by transcommissural exchange. What has survived is one of two very similar persons with roughly parallel memory traces, nearly synchronous emotional states, perceptual experiences, and so on, but differential processing functions. (Puccetti, 1973, p. 352)

Strong reinforcing evidence for the existence of the Daemon can be found in research done into deep trance states. Writing in the late 
1970s, Ernest Hilgard became convinced that we all have another being sharing our lives. Hilgard termed this entity the "hidden observer." In one of his books, Hilgard described a classic test of how this hidden entity is part of our consciousness (Hilgard, 1977). He wrote of a blind student who was hypnotized and, while in a trance state, was told that he would become deaf. The suggestion was so strong that he failed to react to any form of noise, even large sounds next to his ear. Of course, he also failed to respond to any questions he was asked while in his trance state. The hypnotist was keen to discover if "anybody else" was able to hear. He quietly said to the student, "Perhaps there is some part of you that is hearing my voice and processing the information. If there is, I should like the index finger of your right hand to rise as a sign that this is the case" (Hilgard, 1977, p. 186). The finger rose.

At this, the student requested that he be brought out of the hypnotically-induced period of deafness. On being "awakened," the student said that he had requested to come out of the trance state because "I felt my finger rise in a way that was not a spontaneous twitch, so you must have done something to make it rise, and I want to know what you did" (p. 186). The hypnotist then asked him what he remembered. Because the trance was light, the student never actually lost consciousness; all that occurred was that his hearing had ceased. In order to deal with the boredom of being deprived of both sight and sound, he had decided to work on some statistical problems in his head. It was while he was doing this that he suddenly felt his finger lift. This was obviously strange to him, because under normal circumstances he was, like all of us, the "person" who decides on how the body moves. In this case he was not. Not only that, but "somebody else" in his head was responding to an external request that he had not heard. As far as Hilgard was concerned, the person who responded was the "hidden observer."

One of Hilgard's subjects made the following interesting statement about what she experienced, making particular reference to what she sensed was her higher self:

The hidden observer is cognizant of everything that is going on.... The hidden observer sees more, he questions more, he's aware of what is going on all of the time but getting in touch is totally unnecessary. ... He's like a guardian angel that guards you from doing anything that will mess you up. ... The hidden observer is looking through the tunnel, and sees everything in the tunnel. ... Unless someone tells me 
to get in touch with the hidden observer I'm not in contact. It's just there. (Hilgard, 1977, p. 210)

It seems that the deeper the trance, the more chance there is of encountering this being; or so it seems from the work of psychologist Charles Tart. In the 1960 s and 1970 s, Tart was keen to see just how deep a trance state could be brought about by hypnotism. Depth cannot be described solely by the responsiveness to suggestion. Indeed, at greater depths responsiveness can actually disappear. In Tart's experiments, the subjects were required to assign self-consistent numerical values to the depth they subjectively felt.

Tart had a particularly good subject called William who was in the highest 1 percent or 2 percent of hypnotic responsiveness. He had been hypnotized 18 times previously for various reasons, often with an emphasis on depth. William usually gave depth ratings of 40 or 50 , with amnesia experienced at 30 . He had never gone beyond 60 . It was agreed that an attempt would be made to take him much deeper than he had gone before. He was instructed that, at each 10-point interval on a depth continuum, he should remain at that depth as the experimenter had him describe what he was experiencing.

As he went through the levels, he experienced the normal effects: early relaxation followed by a sensation of distance, an increase in peacefulness, and a gradual withdrawal from the environment. Beginning at a level of about 50 on this scale, he began to have distortions of consciousness. These distortions were similar to those reported in mystical experiences. At this stage, the passage of time became meaningless and the body seemed to be left behind, and a new sense of infinite potentiality emerged. However, at a level of 50, another consciousness was experienced, an individual that William described as being him but not him. This "other William" showed that he was fully aware of the experiment and what was going on. What is strange was that this other being was amused by the attempts of the psychologists to understand the human mind. Tart described this event as an "intrusion." The other entity accompanied William from level 50 to level 90 , where it totally disappeared. It was at its strongest at level 70 (Tart, 1975, pp. 191-200).

What is of great interest is that the "intrusion," at the early stages of the now deeper hypnosis of the experience, was amused by William's participation in these experiments. Amusement is not something one would expect of the nondominant hemisphere of the brain. This 
"intrusion" seemed to be a being that knew exactly what was going on and was observing from a position of superiority, not inferiority.

Most "normal" people can live their whole lives without ever being aware of their Daemon. This other self quietly observes what is going on. However, there is strong anecdotal evidence that the Daemon does communicate with its Eidolon on a regular basis through dreams, hunches, and occasionally through direct verbal contact. These "communications," dream or otherwise, are nearly always a warning to avoid a certain course of action. Often those who heed these warnings survive to report the fact. It is as if the Daemon knows the future and actively involves itself in preserving the ongoing existence of its lower self.

The late Julian Jaynes argued that this other entity is in regular communication with its lower self (Jaynes, 1976). His interest was stimulated by a particular vivid auditory hallucination that occurred to him when he was a student. This hallucination stimulated him to research this particular phenomenon. He was surprised to discover that among the Anglo-Saxon population, one man in 12 experienced this form of hallucination. For women it was even more common: one in eight. Indeed, this was quite low in relation to other groups. In Russia the figure was twice as high, and in Brazil almost 25 percent of the population had had, or would have at some stage in their lives, a similar experience. These were normal people, not those under mental or psychological stress. From this, Jaynes concluded that under certain circumstances, many if not all individuals might experience auditory hallucinations, the differences being purely cultural.

For Jaynes, this particularly vivid form of auditory hallucination could explain the universal religious experience of communicating with the gods. It is quite understandable how an individual, living in a culture or a historical period where the existence of gods is unquestioned, could naturally assume the voice to be the words of a god. The curiously portentous and somewhat obscure meaning of what the voice said then reinforced this belief.

However, for Jaynes there was more to it than that. He pointed out that for 99 percent of human evolution, men and women grouped together in tightly bonded, mutually dependent groups. Within these groups each individual had no sense of individuality, no sharp sense of "ego-self." The concept of selfhood came about, according to Jaynes, about the first millennium BC. Jaynes based his theory upon studies that he made of early writings such as Homer's Iliad (circa $1000 \mathrm{BC}$ ). He noted that this book had no reference to concepts such as thought and mind, human actions being the results of the gods willing men to do 
things. From this he concluded that, at some time in the recent past, human consciousness had split into two entities. Not only that, but it was this very process of splitting that brought about self-consciousness.

So what of modern humans? If Jaynes' statistics are to be believed, then many of us interact with our Daemon on a regular basis. As such, the implication is that this "other person" shares our life with us, unseen and unheard, until he or she decides that intervention is needed. Brian Inglis (1990) described various modern equivalents. An example is the tale told by the Italian opera singer Tito Gobbi, who wrote in his autobiography of a time when he was driving far too fast on a precipitous mountain road. As he became more reckless he heard his brother Bruno's voice

so distinctly that he seemed to be sitting beside me, saying "Stop instantly." Instinctively I obeyed, coming to a halt on a wide grass verge, practically the only spot of any width in the whole path. A few minutes later, round the narrow bend came an articulated lorry out of control. (Inglis, 1990, p. 85)

In another example, the writer Philip Paul was walking to work during the London Blitz in World War II when a voice told him to stop. He was, quite naturally, surprised and his rational mind decided to ignore the intruder. He later wrote:

The warning persisted. So, putting a foot on a pile of rubble, I pretended to tie a shoelace. At that moment, the high wall ahead collapsed into the alleyway, filling it ten feet high and burying walkers a few yards ahead of me. (Paul, 1985, p. 25)

In these cases the "voice" saved the life of its lower self. Indeed, in both cases the Daemon showed an ability to see the future. Suffice to say that without these interventions it is likely that neither Paul nor Gobbi would have survived to tell the tale.

However interesting these "Daemonic interactions" are, they are not only rare but also anecdotal. However, there is one psychological state in which the Eidolon is regularly not only in communication with the Daemon, but actually shares some of the sensory inputs of its hidden twin. That state is termed schizophrenia.

\section{Schizophrenia}

Sufferers of schizophrenia show some very curious effects that fail to fit in to any easy explanation. An example is the results of a survey of profoundly deaf schizophrenics, in which 16 out of the 22 individuals 
questioned "heard" the voice of the hidden observer (Rainer, Abdullah, and Altschuler, 1970). The issue here is how persons who have never heard another human voice can somehow hear the voice inside their heads. Indeed, how does a congenitally deaf person understand language, having never heard it? One 32-year-old woman who had been born deaf was continually being told off by her voice about having a therapeutic abortion a few years previously (Rainer, Abdullah, and Altschuler, 1970).

If we are to accept the evidence presented, then it is logical to conclude that the human brain hosts not one but two self-conscious states. These two entities share all sensory inputs, but the seemingly more advanced but elusive being processes the inputs over a far broader area of the sensory spectrum. As such, it is not unreasonable to consider that schizophrenia seems to expose the lower, everyday consciousness, to the sensory environment of the hidden observer. This allows direct communication between the two on a regular, if not continual, basis. It is as if the two consciousnesses overlap in some way.

The causes of schizophrenia remain elusive. However, postmortem examinations show that the number of dopamine receptors in parts of the basal ganglia of the brain is increased in chronic schizophrenia. Could it be that dopamine somehow facilitates access to areas of consciousness not normally available to everyday consciousness? An Eidolon perceiving this "broadband" of information will simply not have the psychic framework to process such an assault on the senses. This assumption seems to be confirmed by the descriptions that schizophrenics give to their perception of the outer world. For example, nurse Norma MacDonald described her schizophrenic break in this way:

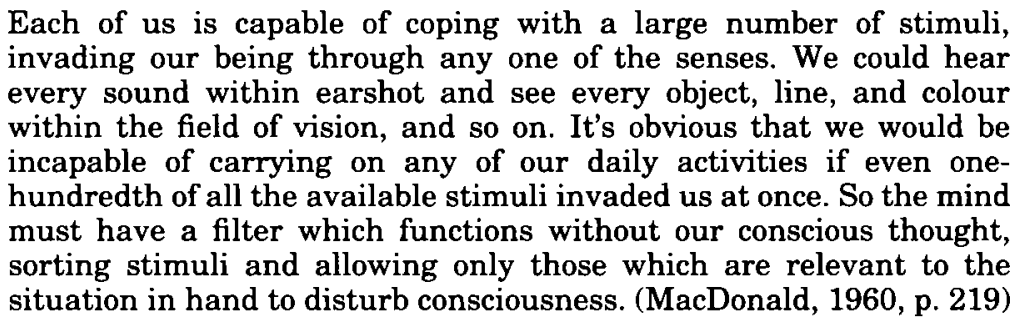

Could this be what the Daemon sees, hears, and senses as regards its environment? As we shall see below, reality - whatever it is that is "out there" - is not the ordered, sensible world that is presented to consciousness through our sensory inputs. It is a holographic miasma 
of colors, sounds, and smells that swirl and buzz. The Daemon perceives the universe as it really is. For an Eidolon to perceive such a world would be to invite insanity and paranoia (from the Greek para nous, "other mind," perhaps a semantic acknowledgement of the Daemon-Eidolon duality). It is no wonder that schizophrenics behave so strangely. They are adrift in a sensory world that is beyond understanding. Within this world they can also sense the presence of another within their mind. They know that the Daemon exists, and this adds to their seeming insanity. However, within this confusion lies another clue to the real reason for our existence in this world: the inescapable fact that schizophrenics, in accessing the world of this other entity, also slip out of time. Eugen Bleuler, the doctor who first coined the term "schizophrenia," made the following observation about his patients' hallucinated voices:

Perceptions can also be transposed into voices without the patient being at all aware of it. In that event the voices become prophetic; a patient hears, "Now someone is coming down the hall with a bucket of water"; then the door opens and the prophecy is fulfilled. (Bleuler, $1950 / 1911$, p. 98)

Here we have not only a direct verbal communication from a Daemon to a schizophrenic Eidolon, but also evidence that for the Daemon temporal flow has no meaning. It knows with certainty what is about to happen next.

This "slipping out of time," knowing what is about to happen next, perceiving the future as a memory of the past, is clearly related, if not identical, to another well-documented but little understood phenomenon, deja vu. An example of this is the following:

A chronic schizophrenic woman who had an exacerbation of her illness seemed to have lengthy episodes of deja vu, which she used in a prophetic way to indicate she knew everything that was going to happen next. For example, she began an interview by stating, "I know all about this. I've been through this same thing many times before. I know what is going to happen." She continued by describing the situation in minute detail to prove her foreknowledge. (Kirshner, 1973, pp. 247-248)

What exactly is happening here? Is dejà $v u$ a short-term vision of the future or is it a memory of a past event? In order to fully appreciate this common sensation, we need to investigate the sensory world of another group of interesting people, those who suffer from what has been known since ancient times as "the falling sickness." 


\section{Temporal Lobe Epilepsy and Déjà Vu}

In a similar, if less extreme, way to schizophrenics, those who suffer from temporal lobe epilepsy report that they perceive reality in a totally different way from the nonepileptic population. Indeed, so unusual are these perceptions that epileptics are continually frustrated by the inadequacy of language. Some report transcendence and a perceiving of the infinite. Others say that within the aura they find God. Self evidently, something very peculiar is taking place. Could it be that, like schizophrenics, epileptics can also access the world of the Daemon? Let us review the evidence.

If you accept my "Daemon hypothesis," you accept that we all have two aspects to our "self." The everyday self, or Eidolon, lives within time and perceives a limited amount of what we term "reality." The other aspect of the self, the Daemon, exists outside of time and knows not only what has happened but also what will happen. As such, any accidental access to the Daemon's perceptions will involve heightened sensory awareness and an ability to foresee the future.

Throughout recorded history, it has been believed that epileptics have the gift of second sight. An example of this is found in the works of the Arabic author Ali Ibn Rabban al-Tabari. Writing in the $9^{\text {th }}$ century, he discussed the illness known as sar'un or "the falling sickness": "The people call it the diviner's disease because some of them prophesy and have visions of wondrous things" (Rabban alTabari, 1928/9 $9^{\text {th }}$ century, p. 138).

Indeed those that could foretell the future, the kähan, were thought to be possessed by the djinn, demons that caused madness and epilepsy. As such, it was believed that another entity took them over during the epileptic attack, and that entity was the one responsible for the prognostications. Here we have evidence of all our suspicions regarding the duality of human consciousness. In the first place, we see the link between possession and epilepsy. We then have the belief that the victim is taken over by another entity, a djinn or demon. And then we have a perceived link between madness (perhaps schizophrenia) and epilepsy. In addition, Rabban al-Tabari wrote that these kähani also had "visions of wondrous things." In our modern terminology, we would describe this as expanded or higher consciousness.

However, there is another factor that is known by neurologists to be inextricably tied to epilepsy, and that factor has profound echoes of the "falling out of time" experienced by schizophrenics. The factor in 
question is dejjà vu. Dejà vu is the most common psychic phenomenon (Neppe, 1983a, 1983b, 1983c). However, it is so common among epileptics, particularly as part of the pre-seizure aura, that it is considered to be one of the classic symptoms.

There have been various attempts to explain this experience, but none has really succeeded. The reason for this failure may be that deja $v u$ is exactly what those who experience it claim it to be: a re-living of an event, brought about by a "hiccup" in temporal perception. But why do epileptics, particularly temporal lobe epileptics, experience deja vu with such regularity? Again, the solution lies in brain chemistry. In the same way that the perceptions of schizophrenics are heightened by the release of dopamine into the brain, so it is that another neurotransmitter has the identical affect on temporal lobe epileptics: it gives accidental access to the perceptions of the Daemon.

A seizure in either of the temporal lobes may be caused by a neurotransmitter known as glutamate. Under normal circumstances, glutamate is the main neurotransmitter within the temporal lobes, and in particular the hippocampus. When a message is transferred from synapse to synapse, it is this chemical that brings about the transfer. Usually this is a harmless process. However, in large amounts glutamate can overexcite the synapses and cause a massive increase in electrical activity. Once started, this rapidly gets out of control and a seizure takes place. However, there is a short period of time when the excess glutamate stimulates neuronal activity without loss of consciousness. This period is perceived by the person affected as the pre-seizure aura. It is this increased activity, while still allowing consciousness, that brings about the Eidolon's access to the world of the Daemon. Thus, in the same way that dopamine allows the schizophrenic to open the door, so it is with glutamate in temporal lobe epilepsy.

During this flood, there can be an immediate loss of temporal awareness. For a few seconds, the Eidolon glimpses reality as it really is, and sees time as an illusion. For that period, the Eidolon's "specious present," as psychologist William James (1950/1890, p. 613) termed it, becomes longer. In its confusion, the Eidolon thinks that it is seeing a re-run of the previous few seconds of perception. This is not the case. What has happened is that the glutamate flood has temporarily nullified the usually effective censorship of real perception. This is perceived as a deja $v u$. Within a few seconds, the processes of censorship regain control, and either the seizure begins or normal perceptions are regained. 
So far I have presented evidence that all human beings consist of not one but two interrelated entities. These entities, termed the Eidolon and the Daemon, share the same sensory inputs of sight, sound, taste, touch, and smell. However, the Daemon perceives reality as a riot of swirling colors, sounds, and sensations, not as the ordered world presented to the senses of the Eidolon. For some individuals, specifically schizophrenics and temporal lobe epileptics, access to the Daemonic worldview is facilitated by neurotransmitters such as dopamine and glutamate. The Daemon also perceives time in a totally different way from the Eidolon. For the Daemon, time does not flow from past to present, but is seen as a continuum where past, present, and future all coexist.

So which version of reality is real? Is it the day-to-day normality of the world of the Eidolon, or is there another reality hidden behind the phenomenological world that only the Daemon and the occasionally confused Eidolon perceive? Is the film The Matrix (Wachowski and Wachowski, 1999) more than just a fiction? The answer lies in the fundamental nature of reality itself, which, if modern quantum physics is to believed, is not at all as it seems.

\section{Quantum Physics}

Matter may appear solid, but this is a perceptual illusion. Its basic constituents are fuzzy waves of probability. All material in the universe owes its solidity to billions upon billions of molecules bunched so closely together that they make up a physical mass. These molecules are, in turn, made up of atoms, small, indivisible "lumps" of matter. However, painstaking experimentation by physicists has shown not only that these little lumps consist mostly of empty space, but also that the particles making up the small percentage of "solidity" are themselves mere waves of probability.

The late David Bohm asserted that these findings of modern particle physics implied that there is a deeper reality beneath the quantum world. This underlying or "implicate order," as he termed it, links all things. The concept of an underlying implicate order linking all things can explain action at a distance, telepathy, collective consciousness, and similar phenomena. However, Bohm also believed that external reality is also not quite as it seems. He considered that the seemingly erratic and illogical behavior of the subatomic world could be explained if every part of the observed universe was intertwined with every other, or, as he 
termed it, "enfolded." Underlying our perception of separate things is a hidden order of wholeness that Bohm likened to a flowing stream:

On this stream, one may see an ever-changing pattern of vortices, ripples, waves, splashes, etc., which evidently have no independent existence as such. Rather, they are abstracted from the flowing movement, arising and vanishing in the total process of the flow. Such transitory subsistence as may be possessed by these abstracted forms implies only a relative independence or autonomy of behaviour, rather than absolutely independent existence as ultimate substances. (Bohm, 1980, p. 48)

This enfolding involves everything that exists, including human consciousness. Bohm wrote:

In the implicate order the totality of existence is enfolded within each region of space (and time). So, whatever part, element, or aspect we may abstract in thought, this still enfolds the whole and is therefore intrinsically related to the totality from which it has been abstracted. Thus, wholeness permeates all that is being discussed, from the very outset. (Bohm, 1980, p. 172)

Bohm likened the universe to a huge hologram, containing copies of itself within its own structure. He termed this the "holomovement." If a holographic picture plate is smashed, each broken shard will contain a small but perfect replica of the original picture. So it is with the holographic universe. For example, if Bohm is to be believed, the Milky Way can be found in a thumbnail, and within that Milky Way will be the Earth containing that same thumbnail (Bohm and Peat, 1987).

Bohm then expanded upon the hologram analogy to posit that the world outside of consciousness is a cacophony of swirls and splashes, in the same way that the image on a holophotographic plate is when illuminated with normal light. It is only when laser light is shined upon the plate that the image leaps out in its three-dimensional glory. So it is with "reality": we can make sense of the confusion only when consciousness, in the same way as the laser, "illuminates" the incoming images and sounds inside the brain. In this way we again create our own internal and subjective projection of reality.

According to neurologist Karl Pribram, the hologram idea also holds true also for memory. Pribram started on his quest in 1966 when he proposed that the brain might interpret information the same way a hologram records an image. He suggested that the fine fibers in the nerve cells digitize incoming information and store the data in this format. The brain then decodes these stored memory traces the way a hologram decodes, or more accurately de-blurs, its original image. 
Pribram proposed that the brain itself acted as a form of lens, a lens that brought the blurred potential of a holographic universe into sight, sound, color, and all the other sensory inputs that make the "outside" become "inside." Just as the image on a holographic photographic plate is a swirl of blurs and fuzziness, so it is with the universe "out there." It is only when the lens of the brain, acting like the laser light on a holographic plate, brings out the three-dimensional image that the universe comes into being. As Pribram said:

Maybe reality isn't what we see with our eyes. If we didn't have that lens - the mathematics performed by our brain - maybe we would know a world organized in the frequency domain. No space, no time just events. Can reality be read out of that domain? (Ferguson, 1982, p. 22)

This revolutionary explanation of consciousness and its relationship with "reality" has recently come to the attention of mainstream science. In August 2003, Scientific American took the subject as its cover story, in which Jacob Bekenstein wrote:

An astonishing theory called the holographic principle holds that the universe is like a hologram: just as a trick of light allows a fully threedimensional image to be recorded on a flat piece of film, our seemingly three-dimensional universe could be completely equivalent to alternative quantum fields and physical laws "painted" on a distant, vast surface.... Physicists hope that this surprising finding is a clue to the ultimate theory of reality. (Bekenstein, 2003, p. 60)

This is reality as perceived by the Daemon, a being that exists in a sensory world very different from its Eidolon. It exists outside of time and, presumably, space. It perceives "reality" as it really is: a confusing mass of signals and images illuminated by the whole electromagnetic spectrum. To beings not ready for such an explosion of inputs, such as Eidolons, this would drive them insane. Could it be that the chemical imbalances that cause schizophrenia bring about aberrant behavior because they change the "frequency" by which the brain receives incoming data? The "tuning" moves into the frequency normally reserved for our "hidden observer," and the sensory floodgates are flung open to drown the unsuspecting Eidolon. Physicist Raynor Johnson in his tower analogy described how this can seem to a schizophrenic Eidolon. He said:

We are each rather like a prisoner in a round tower permitted to look out through five slits in the wall at the landscape outside. It is presumptuous to suppose that we can perceive the whole of the landscape through these slits-although I think there is good evidence 
that the prisoner can sometimes have a glimpse out the top! (Ferguson, 1973, p. 226)

Pribram quite reasonably argued that reality is not perceived directly, but through this internal projection process. A threedimensional copy of reality is projected by the brain (lens) and then experienced by the internal observer. The images thus generated are then stored within the structure of the brain in the same way that a digital video disk (DVD) stores pictures and sound images. These images do not degrade and can then be recalled at a later date. The Daemon perceives reality "before the lens," as it were. The Eidolon, on the other hand, sits on the other side and views a decoded, reassembled, and recorded version of what is "out there." This presentment to consciousness may be recordings of events that took place ten minutes, ten months, or ten centuries ago. For the Eidolon, there is no way of telling, because the illusion of reality is so close to the real thing that he or she simply cannot tell the difference.

The idea that reality, as it is perceived though our senses, is only a fairly accurate approximation of that reality was termed the "ecological model of perception" by Pribram. He felt that this viewpoint, however comforting, is inadequate in explaining perception, and he offered his "holographic model" to address these issues. In this model, images are constructed when input from the inferior temporal cortex activates and organizes the holographic store. Images are then produced and

are therefore as much a product of the "information residing in" the organism, as they are of "information" contained in the environment. Philosophically speaking, the holonomic model is Kantian and Piagetian; the ecological model partakes of a critical realism. (Pribram, 1977, pp. 88)

In other words, the internal projection of the external world is mixed with internally generated subjective thoughts, feelings, and interpretations. Put simply, we take external "reality" and we make it into our own subjective internal world: we all create our own version of reality.

Pribram justified this in a very simple and straightforward way. $\mathrm{He}$ cited examples of people who suffer from severe perceptual problems such as macropsia and micropsia, where a person perceives objects as being much bigger or much smaller than other people do. Individuals with macropsia see these objects in much more detail than "normal" people do. He gave an example of one of his own patients who, after a blow on the head, suffered bouts of severe vertigo. At the end of an 
attack he would see the world upside down. His visual system was interpreting the input from the retina in totally the wrong way. This would persist until another vertigo attack placed his vision the right way round. The implication here is clear. This man's visual system was acting like a television that was confusing the signal, not like a person who was directly interfacing with "out there."

As these internally generated versions of reality are, in a very real sense, a recording, it is therefore reasonable to regard them as "memories." These endogenous memories are as different from normal memories as an IMAX cinema with three-dimensional virtual reality images and surround-sound is from a black-and-white photograph. A totally believable three-dimensional multimedia re-living of the event, with such clarity that it is impossible to differentiate it from the original, engulfs the observer. This I term the "Bohmian IMAX."

The idea that such memories not only exist, but also can be spontaneously re-lived, can be supported by the events recorded by neurosurgeon Wilder Penfield. Penfield, having placed an electrode on the exposed cortex of his conscious patients, was able to stimulate total memory recall for the patient. Some of the patients insisted that these were not simply memories, but an actual re-living of the recalled event. It was as if they had gone back in time. Penfield wrote the following telling comments:

Time's strip of film runs forward, never backward, even when resurrected from the past. It seems to proceed again at time's own unchanged pace. It would seem, once one section of the strip has come alive, that the response is protected by a functional all-or-nothing principle. A regulating inhibitory mechanism must guard against activation of other portions of the film. As long as the electrode is held in place, the experience of a former day goes forward. There is no holding still, no turning back, no crossing to other periods. When an electrode is withdrawn, it stops as suddenly as it began.

A particular strip can sometimes be repeated by interrupting the stimulation and then shortly reapplying it at the same or a nearby point. In that case it begins at the same moment of time on each occasion. (Penfield and Roberts, 1959, p. 53)

Penfield concluded:

Every individual forms a neuronal record of his own stream of consciousness. Since artificial re-activation of the record, later in life, seems to re-create all those things formerly included within the focus of his attention, one must assume that the re-activated recording and the original neuronal activity are identical. Thus, the recorded pattern of neuronal activity may be considered much more than 
a record, for it was once used as the final stage of integration to make consciousness what it was. (Penfield and Roberts, 1959, p. 54)

The implication therefore is that, as Eidolons, we all exist in a threedimensional projection generated by our own brains. What we perceive is an illusion, an illusion very much in keeping with the central tenets of Eastern religions such as Buddhism and Hinduism. A Hindu would understand this to be the state known as maya, and Buddhist would recognize it as samsara. So the "reality" that you perceive as "out there" is not out there at all. It is all an illusion. Rather like the little boy who pulled himself off the ground by his bootstraps, so you create your own universe in which you, or more specifically, your brain, is a part.

Indeed, at its most fundamental level, matter itself shows this reciprocity to such an extent that physicist Geoffrey Chew called his model of reality "bootstrap theory." Chew was particularly interested in hadrons, strongly interacting subatomic particles. For Chew, "each particle helps to generate other particles, which in turn generate it" (Chew, Gell-Mann, and Rosenfeld, 1964, p. 74). Or, to put it another way, every hadron is made up of combinations of other hadrons, including itself. And so it is with your brain in your universe, and my brain in mine. However, the suggestion that the universe is an internally created illusion implies that each consciousness carries within its brain a fully functioning, three-dimensional version of that universe. As such, to accept such a proposition one has to accept that there are literally millions upon millions of personal universes, each one being generated by the thought processes of a single conscious observer. Can this be possible?

\section{The Many Worlds Interpretation}

Believe it or not, the answer is, "Yes." The observed behavior of subatomic particles has forced scientists to accept one of two seemingly conflicting theories: the statistical or "Copenhagen interpretation," and the "many worlds interpretation." Experimentation has shown that entities such as electrons need an act of observation to bring them into reality. Before they are observed these things are nothing but a wave of probabilities, or as they should be correctly termed, "wave functions." They need an "observer" to confirm their probability of location into an observed certainty and, in doing so, collapse them into a solid point of matter. Without an observer they cannot become real. Therefore 
a universe with no observers is a physical impossibility, because without a conscious observer to collapse the wave function, matter cannot exist.

It is important to realize the implications of this Copenhagen interpretation. All matter, including tables, chairs, the sun, and your brain, are made up of these particles. A moment's reflection will bring home the inherent weirdness of such a belief. If we are to accept that consciousness is a function of brain processes, then consciousness needs matter in order to exist. But matter needs consciousness to come into existence. This, like the boy who pulled himself into the air by his own bootstraps, is probably the ultimate paradox.

Such was the paradox that prompted physicist Erwin Schrödinger to propose a thought experiment, to prove the absurdity of such a belief. Schrödinger asked us to imagine a cat placed inside a sealed box with no windows. Also inside this box is a bottle of deadly gas. Poised above this box is a small hammer being held back by a latch. In turn, this latch is connected to a detector. This detector is programmed to scan a piece of radioactive material for the decay of one particular atom, an event that is known to have a 50-50 probability of taking place or not taking place.

If the atom does decay, the detector will send a signal to the latch, instructing it to release the hammer. The hammer then falls upon the bottle, smashing it and thus releasing the poisonous gas, resulting in the immediate death of the cat. Conversely, if no decay takes place, then the hammer does not fall and the cat continues to live. The objective state of the cat cannot be confirmed until the box is opened and an observer looks inside. According to the Copenhagen interpretation, it is this action of observation that facilitates the collapse of the probability wave, which in turn will bring about the decay or non-decay of the atom in question. Thus, until observed, the cat is in a curious alive-and-dead situation (Schrödinger, 1935).

For Schrödinger, such a proposition was clearly absurd. However, a young researcher named Hugh Everett proposed a simple revolutionary solution to the dead-and-alive state of the cat. He explained that the universe could accommodate both states by splitting into an identical copy of itself at the point of the quantum event. In one universe, the atom does not decay and therefore the cat lives; and in another, the particle does decay and the cat dies. There are then two observers, each in his or her separate universe, who open the box to see either a dead or alive cat (Everett, 1957).

At first sight, this seems even more preposterous than the Copenhagen interpretation. For years, those who doubted such an 
alternative version of reality were happy that such an experiment could not be reproduced. However, in 2000 a group of researchers reported that they had reproduced the impossible: an equivalent to Schrödinger's cat experiment (Friedman, Patel, Chen, Tolpygo, and Lukens, 2000). Their experiment used superconducting quantum interference devices (SQUIDs), ring-shaped devices in which persistent currents, made of billions of pairs of electrons, can circulate in either a clockwise or a counterclockwise direction without decaying. The experimenters started with a current flowing in one direction, and then illuminated the SQUID with microwaves that excited the system to a higher-energy state. The system could then tunnel from its original state, with the current flowing in the one direction, into a state with the current flowing in the opposite direction, and back again.

The question is essentially whether the system remembered or forgot its quantum state as it tunneled. To answer this, the research team measured the probability of finding the current flowing in the opposite direction as the shape of the double-well potential was changed. The results were exactly as predicted by assuming that the system was in a macroscopic superposition of the two states. These results provided clear evidence that multiple universes do exist. Indeed, recent work by physicist David Deutsch has shown that we can actually measure the effect that these alternative universes have on our version of the newly termed "macroverse" (Deutsch, 1998).

If the results of the SQUID experiment can be taken at face value, then Everett's idea becomes more tenable as an alternative to the statistical or Copenhagen interpretation. However, in doing so, it does not invalidate the more solipsist implications of the Copenhagen interpretation. Indeed, if every possible outcome of every action takes place in at least one of the multiple versions of reality, then it can be argued that each conscious being exists in its own version of reality. If this is the case, then can it not be argued that in your own universe you have to continue to exist, because to die would entail your universe ceasing to exist? One of the implications of the SQUID experiment is that events at the quantum level of reality can effect those in the macroscopic world. Up until then, it was always assumed that the weird behaviors of particles could never spin over to our world. However, if this is now the case, there is one place where the world of quantum behavior does interface with our world, and that place is in the brain.

Within each brain, human or otherwise, are cells called neurons. Each neuron interfaces with dozens of others across small gaps called 
synapses. These synaptic gaps are extremely short, about 200 to 300 angstroms across (about 2-3 millionths of a centimeter). Messages are transferred across the brain through these synapses. Depending upon what is being thought, certain synapses transfer electric current between them in the form of calcium ions in a process called "firing." Some neurons will fire across the synapse and others will not. So rather similar to traffic lights that are red or green, the flow of messages across a brain can be channeled in various directions. The width of these synaptic gaps is so small that they approach the atomic scale of dimensions. At this point, quantum events become important. It is therefore possible that a synapse, teetering on the edge of its "firing threshold," could be influenced by an event at the quantum level. In other words, the firing or non-firing of a neuron may depend upon a similar quantum event as that outlined in the Schrödinger's cat thought experiment.

Consider a calcium ion, which has a 50 percent probability, according to Schrödinger's equations, of activating its target receptor. Imagine that that receptor will make the difference between two possible states of mind. Imagine one of those split-second decisions being influenced by this event. For example, a subject is in his car approaching a set of traffic lights that are amber. He makes a decision whether to accelerate and go through the lights or to hold back and stop. The result of this decision is transferred across the synapse by neurotransmitters. This neurotransmitter tells his leg to press on either the accelerator or the brake. At that point, we have a quantum event taking place. He presses the accelerator, crosses the lights, and his car gets hit side on by a large truck. He dies instantly.

However, in a very real sense, his death is only one outcome. In another, he may have decided to stop. At that point, we have two alternate realities: one dead driver and one alive. The driver followed his own world line and remained alive. In the world line of any bystanders, our subject died. I argue that the subject's perceived universe will always split in such a way to ensure his or her personal survival. The subject may die in my universe, but will go on and on in his or her own. And I am not alone in this opinion.

Physicist Max Tegmark (1998) proposed a thought experiment that applied the latest findings of quantum physics to prove that my angle on immortality may be a scientifically provable reality. Tegmark imagined a machine gun attached to a device that measures the $z$-spin of a subatomic particle. All subatomic particles have a z-spin, which can be "up" or "down." The direction of spin is entirely random and, as 
such, cannot be predicted for any single particle. If the detector senses a particle that has "down" spin, then it instructs the machine gun to load a single live bullet into the stock. If the particle spin is detected as being "up," the gunstock remains empty, with the weapon just making an audible click.

In order to test the gun, the experimenter asks an assistant to pull the trigger 10 times. According to all quantum mechanical interpretations, the experimenter will hear a random sequence of live shots and duds. The experimenter then decides to put his or her life on the line for science. According to logic, the experimenter will hear, at the first trigger pull, either a click - if the gunstock was empty - or nothing - assuming that the bullet enters the experimenter's brain causing immediate death. A lucky experimenter may hear two or three clicks before a bullet shatters his or her brain. However, according to the "many worlds interpretation," the experimenter will hear a click with 100 percent certainty. As such, the experimenter will end the experiment having heard 10 clicks and will still be very much alive.

The experimenter will naturally conclude that there is no such thing as a random event in the quantum world. All subatomic particles that are randomly linked to the machine gun have "up" spin. Indeed, if the experimenter decided to continue the experiment for all eternity, he or she would never find a "down" spin particle. "Down" spin particles will simply cease to exist in the experimenter's world. However, if the experimenter moves away from the gun for a few "tests," he or she will note that probability does still hold and that bullets will be fired 50 percent of the time. Things, however, are not so good for the assistant who was asked to pull the trigger. The gun went off after the fourth attempt in the assistant's world, and he or she was arrested and given a prison sentence.

So in order for the observer's personal universe to continue, that observer must continue to observe. Within that universe, the observer therefore cannot die, and the "many worlds interpretation" ensures that this is the case. In each personal time-line fatal accidents are always avoided, immunity to all terminal illnesses is developed, and a seemingly charmed life is lived. I stress "in the observer's universe" because in many other universes they do die, at least from the viewpoint of the "observer" responsible for those other universes. And that is how we experience the very real death of others. They die only in our universes, whereas in their own they go on enjoying the threedimensional internally-generated life review, sitting in the front row of my Bohmian IMAX. 


\section{The Daemon's Perspective}

What I have presented thus far is a series of interrelated observations leavened with empirical examples from the worlds of neurology, psychology, particle physics, and consciousness studies. What I am suggesting is that all self-aware beings consist of not one singular personality but two. These two entities, known from classical times as the Eidolon and the Daemon, have a curious symbiotic relationship. The less developed Eidolon, usually known as "I," is, except in certain psychological states, totally unaware of its more developed partner, the Daemon. However, the Daemon seems to be very aware not only of its twin but also of the way in which their shared life will develop. Indeed, there are many well-documented cases of prophets, seers, and clairvoyants whose ability to predict the future depended upon the prognostications of another being, such as Socrates' "Divine Sign" and Nostradamus' "Divine Splendor."

By various means, including dreams, hunches, and auditory hallucinations, the Daemon ensures the ongoing survival of its Eidolon. In doing so, it may change the future time-line of its unitary self. In fact, it changes nothing as regards the perception of other consciousnesses. All it does is send itself and its partner down a different alternative version of reality, and in doing so enters another universe, one of trillions to choose from.

I have presented evidence that all this takes place in a highly personalized version of reality, a version of reality projected into the consciousness of the Eidolon, who in blissful ignorance carries on with its life. For the Daemon, it is very different. It has already viewed the Bohmian IMAX, this being its second or even $10,000^{\text {th }}$ viewing of this life. Sometimes there is a metaphorical "jump" in the recording, perhaps brought about by a leaking of certain neurotransmitters across the synapses. For a split second, the Eidolon accesses the senses of the Daemon and has a feeling that it has lived this event or circumstance before. This is a deja vu.

So these are the clues, but the clues to what? This article is in a journal that deals with near-death experiences, and yet $I$ have barely mentioned this phenomenon. However, all the above examples can be dovetailed together to give a satisfactory, scientifically based explanation as to what really is happening at the point of death, an explanation that will possibly be philosophically acceptable to all within the field, from theists to atheists. Let us now look at 
what may happen at the point of death according to the Ferryman Thesis.

\section{The Point of Death}

First, we need to understand the role of the neurotransmitters, which has to do with what I have termed the "quantum Zeno effect." This "quantum Zeno effect" is named after Zeno of Elia who, in an effort to show that motion was an illusion, devised his famous paradox of Achilles and the tortoise.

Zeno suggested that a race be arranged between the fleet-footed hero Achilles and a much slower tortoise. Because Achilles can run 10 times faster than his reptilian opponent, he agrees to give the tortoise a 10 meter head start. The starter's gun is fired and Achilles swiftly runs the 10 meters. However, because we know that he can run ten times faster than the tortoise, the tortoise will have already walked one meter closer to the finishing line. Achilles, still behind by the one meter, runs that meter as fast as he can. However, on reaching the $11^{\text {th }}$ meter, he discovers that the tortoise has walked a further centimeter. Achilles runs that centimeter, but in the time it takes him to do so, the tortoise has progressed a further millimeter towards the finishing line. Rushing along the millimeter, Achilles discovers that he is still a tenth of a millimeter behind. One can go on literally to infinity, but Achilles will never overtake the tortoise.

Obviously, in reality, Achilles shoots past the tortoise and wins with ease, but the philosophy behind this paradox has an underlying truth when it is applied to time. But more interesting is that neither the tortoise nor Achilles ever reaches the finishing line. They just move in smaller and smaller amounts of distance.

The evidence presented in this paper suggests that this is what happens to dying persons as they approach the point of death. Instead of meters, we have units of time. Let us call them "chronons." At the moment that death becomes unavoidable, chemicals are released into the brain. These chemicals influence how the Eidolon perceives time. As regards the perceptions of the Eidolon time, seems to slow down. The human brain is very flexible in its perception of temporal flow: drugs, mood, and metabolism all contribute to time's perceived duration.

Massive chemical changes take place in the body at the point of death. The chemicals released at that point are virtually identical to those released during an epileptic seizure. Juan Saavedra-Aguilar and 
Juan Gómez-Jeria (1989) pointed out the link between NDEs and temporal lobe epilepsy, suggesting that the stress brought about by a close brush with death leads to a release of a particular class of chemical called neuropeptides and specific neurotransmitters such as endorphins, dopamine, and glutamate. These chemicals become particularly active in the limbic and temporal lobe areas of the brain and cause psychological effects during near-death trauma identical to those experienced by epileptics during a pre-seizure aura. It is therefore reasonable to conclude that all the changes in perception, particularly in terms of time perception, reported by epileptics are experienced, albeit in a much greater intensity, at the point of death.

In this way psychological time, for the dying person, begins to slow down. In effect, they "fall out of the time perspective" of any observers who may be witnessing the death. For dying persons, each second may take twice as long to pass as the previous second. As such, their consciousness moves away from the observer's, whose seconds continue to be seconds.

What we have here is a literal interpretation of the scientific concept of half-life; only in this case it is a real life that we are talking about. Radioactive substances decay in such a way that they lose half of their radioactivity in a given period of time. For example, the radioactive isotope cobalt-60, used in radiotherapy, has a half-life of 5.26 years. Thus, after that interval, a sample that originally contained eight grams of cobalt-60 would contain only four grams of cobalt-60 and would emit only half as much radiation. After another interval of 5.26 years, the same sample would contain only two grams. However, in a real example of Zeno's paradox, in the next 5.26 years the cobalt-60 is only one gram, and in the next it decreases to half a gram. However and this is a crucially important point - the amount of cobalt never reaches zero; it just halves every 5.26 years from now to eternity. Put simply, it suffers from the same problem as Zeno's Achilles: it never arrives. And so it is with our life force. We also have a real half-life that, within our own ever-shrinking temporal awareness, is a full-life.

But glutamate and dopamine also manage to do something else: they awaken the Daemon.

This is total supposition on my part, but I propose that sometime in your own personal past, you once did live a real life in a real universe. It is that life that laid down the template by which all your other lives were lived. In that first life, your Daemon and Eidolon, like Julian Jaynes' preconscious ancients, lived as a unitary being. Your consciousness was singular and the Daemon was totally unaware of 
itself as an entity separate from the Eidolon. It is reasonable to conclude that certain people with temporal lobe epilepsy or schizophrenia may have the duality from the start.

Suffice it to say the singular consciousness lived its life for the first time. Its holographic memory banks busily recorded every thought, feeling, sensation, emotion, and event that happened during that life. Because these recordings were being made as consciousness perceived them, they could not generate deja $v u$ sensations. This is analogous to the fact that you cannot watch the ending of a recorded television program before the videocassette has finished recording. At this stage of human development, the future simply did not exist. This is why some people have never experienced a dejà vu: they are quite literally "first timers," living their life for the first time.

As death approached in that first life, endogenous chemicals flooded the brain. These stimulated the Daemon into wakefulness and selfawareness. Although shocked, it quickly realized what it had to do. Imagine the scene at a road accident. The paramedic is desperately trying to save the life of a badly injured man, and realizes that he is about to die. Six seconds before he does die, the endorphins, dopamine, and glutamate flood his brain and release his Daemon. As he lies on the ground, the endogenous drugs affect his psychological time.

The time between the sixth and fifth second before the injured man's death takes one second in the perception of the concerned paramedic. However, for our dying man, the very nature of time is changing. For him, that second takes two seconds to pass. The next half-second (which is another second for the paramedic) takes four seconds for the dying man, and the next quarter-second (again another second for the paramedic) takes eight seconds. Within three seconds of "normal time," our two people are existing in totally different time-worlds. The dying man is still back in the first second and existing in an evershrinking "chronon" of time. His individual seconds are dividing as time progresses. In the same sense that Achilles never overtakes the tortoise, so it is that the dying man never reaches his actual point of death. The curiosity, however, is that in the temporal world of the paramedic, the man dies.

Let us now go back again to my example of the person jumping the traffic lights. In the same way that the collision with the large truck never happens in his world, so it is that the injured man in this new example never dies in his. The reason is simply that the endogenous drugs that flood his brain as death approaches bring about a loss of temporal awareness. As we saw with schizophrenics and temporal lobe 
epileptics, the neurotransmitters dopamine and glutamate literally flood the brain.

It has been well recorded that glutamate manifests itself during periods of high anxiety and stress. It is also known that glutamate in large doses can overexcite the synapses and cause a massive increase in electrical activity. Once started, this rapidly gets out of control and an epileptic seizure takes place. Our dying man has therefore moved out of time (and, it must be said, space), and is inhabiting a world within his own mind. He has, in effect, unlimited time; but what is this time for? In answering this question we must return to the Daemon.

The Daemon is now aware of what its task is to be. It is responsible for ensuring that the life review takes place, but not as it is known from the reports of NDErs. The standard description of the life review is often similar to "my life passed before my eyes in a split second." But that is only the way the life review is recalled by a person who has returned to "normal" consciousness and "normal" time. In the real run that is stimulated by an actual death situation, the review takes place at normal speed, in a minute-by-minute equality. Each minute of the life record is perceived by the Eidolon as an actual minute. Put another way, the Eidolon lives its life again in real time.

At a microsecond before death, the dying person's consciousness is flooded with new images, images of rebirth. The Eidolon finds itself coming into a virtual reality world as a newly born baby. Its memory banks wiped clean, it remembers nothing of its previous life. It begins afresh in a world created from recovered memories. As described by Penfield's patients, every sound, feeling, and emotion is reproduced in perfect fidelity. As far as the Eidolon is concerned, this is all new. However, this second life has one major difference from the first one. It has a conscious and aware Daemon who has a knowledge of everything that is about to take place. As the child grows in this second life, the Daemon keeps a watchful eye over its progress. It experiences everything, and in dreams may communicate subtle changes to the progress of this second life.

As we have already seen; as the Eidolon-child becomes older, circumstances may occur in which either by accident or design the Daemon causes a "glitch" in the program. The Eidolon will be confused at these strange sensations, and may have a feeling that it has lived these events before, that it remembers what will happen next. On reading up or commenting to others, it will discover that these curious sensations are very common and are called dejà vu. 
There may be occasions when the Daemon wishes to change the course of action followed by its Eidolon. The Daemon may manifest itself in many ways, as a voice in the head, a dream, or even a doppelgänger. In this way it can maneuver its Eidolon into a better position or into a situation were it may learn from experience. I term these situations "temporal mutations," and they work in the same way that Darwinian mutations take place in nature.

However, this proposal regarding "temporal mutations" could be seen as a flaw in this carefully constructed structure. If the second life is little more than a virtual reality projection of the first, how can it be changed? After all, we cannot change the ending of a film if we do not like the plot. The difference lies in the "many worlds interpretation" of quantum mechanics and in Bohm's concept of enfoldment. Remember that the dying person has moved outside of time and space, and exists in his or her own personal reality. However, this reality consists of a universe of his or her own making. Real people with real motivations populate each universe. Actions taken by one person will simply bring about another universe. In this way, all possible events can (and will) take place. Added to this is the idea that each universe enfolds and is contained within every other universe. In this way, changes made in one lifetime can and will affect the lives of others within their own consciousnesses. In this way, one can make right any wrongdoings of the previous life.

And so the human "soul" evolves in the same way that an animal species evolves. Equal to each Darwinian generation is a life, each one subtly changed from the last one. Note that my theory involves multiple, rather than singular, life re-runs. Like the character Phil Conners in the film Groundhog Day (Ramis, 1993), we each have endless lives to get things right. The mechanism is simply a repeat of the end of the first life. At the end of the re-run, death again approaches, and is again denied by the person's consciousness slipping out of time. Psychological time again slows down in an exponential way, leaving Charon yet again with an empty boat.

For both the Daemon and the Eidolon, the approach of death is a stressful time. However, in terms of our own research into the possibility of the Ferryman Thesis, it is also the time that the interaction between the two should be at its most intense. The evidence seems to support this contention, in that the Daemon seems to become visible to the dying Eidolon. The interesting example below is taken from the work of psychologists Karlis Osis and Erlendur Haraldsson:

A college-educated Indian man in his twenties was recovering from mastoiditis. He was doing very well. He was going to be discharged 
that day. Suddenly at 5 am he shouted, "Someone is standing here dressed in white clothes. I will not go with you!" He was dead in ten minutes. Both the patient and the doctor expected a definite recovery. (Osis and Haraldsson, 1977, p. 44)

In this case, the patient did actually die, indicating that the "being of light" may be seen as part of the "real thing" as well as in "near misses." Chemicals released in the brain prior to death appear to create a level of awareness in normal consciousness that allows perception of our Daemon, or higher self. In the case described by Osis and Haraldsson, the Daemon decided to be seen as a being that could not be recognized as another version of the self. However, there has been a long held belief that to see one's double is a portent of death (Maack and Mullen, 1983; Rank, 1971/1925). Could this have come about when the dying reported that they could see their own Daemon as a doppelgänger? It is reasonable to conclude that, whereas some Daemons show themselves at this point, others take on the appearance of whatever person or religious archetype will instill in the dying person a feeling of happiness and joy.

It is usually reported that the Daemon spontaneously appears and that there is no perception of the bifurcation of the mind. However, it is logical to conclude that this spontaneous appearance must take place in order for the Daemon to be perceived as being "out there," as opposed to a voice in the head or a hunch. It seems that we can sometimes actually sense this splitting process. The Gnostics considered that at the point of death the human soul splits into two separate entities. Indeed, in the Gnostic Gospel of Thomas (61:1), Jesus made this very cryptic comment: "Two will recline on a couch; one will die, one will live" (Miller, 1992, p. 314).

So at the moment of death, our Eidolon is transported back to the point at which the embryo becomes a person, the point where some form of consciousness enters the growing brain. If this theory is correct, then this can take place as soon as the neurons have developed sufficiently for the Eidolon to attach itself. At this point, the brain "wakes up" and becomes, if not fully conscious, at least aware in some basic way. Indeed, at this point dreaming will begin. The Eidolon has the opportunity to review and reflect upon what took place in its previous life, possibly under the guidance of the Daemon. This form of pre-natal dreaming is a form of what is termed "active sleep." According to biologist Lyall Watson, the developing fetus seems to spend most of its time doing it (Watson, 1979). The 
question is: what can a being who has had absolutely no experience dream about?

At birth, the density of neurons within the brain is, in a relative sense, fairly small. It is only after birth that the cortical dendrites grow and the glial cells multiply. As such, whatever mental activity takes place will be very basic. The newly born child has no concept of self or identity. It has no real consciousness, just an ability to react to external stimuli in an autonomic way. However, if this is the case, how is it that certain people claim they can remember being born, and some even claim they can remember events in the womb?

Psychiatrist Stanislav Grof came across anecdotal evidence that implied that our ability to perceive our environment and lay down memories starts very early. Patients accurately described characteristics of the heart sounds of their mother, the nature of acoustic phenomena in the peritoneal cavity, specific details of blood circulation in the placenta, and even details about the various cellular and biochemical processes taking place. They could also describe the thoughts their mother had had during pregnancy and events such as physical traumas she had experienced. When verification was later available by talking to the mother herself, these memories were confirmed (Grof, 1976).

Grof's results were reinforced by the subsequent report of a child remembering his own birth by Caesarean section (Laibow, 1986). The child in question was extremely precocious in terms of his general development. On day 1 , he was able to lift his head, focus, and follow an object with his eyes. He was speaking recognizable words at 3 months and sentences at 5 months. However, it was at age 2 , while sitting in the bath, that he asked a startling question of his parents. He wanted to know why the lights were so bright "when I was new." On being asked what he meant by "new," he explained that he meant "being born," and said there were many things he did not understand about this.

The child did not stop with that. He went on to ask why it was that the light was circular and intense where he was but dim elsewhere; why the bottom half of faces were missing, with a green patch there instead; why someone had felt his anus with a finger; why he was put in a plastic box and taken somewhere; why liquid was put in his eyes so that he could not see; and what was inserted in his nose that made a loud sucking sound. Indeed, he went on to describe not only other experiences of his birth but also experiences he had had in the womb. 
Laibow reported that the child had never seen a surgical unit nor surgical green masks, and did not know that silver nitrate solution was routinely used in the eyes of newly born babies, nor had the child seen or heard a suctioning device used in the nostrils except on the occasion of his own birth (Mollon, 1995).

This case seems to show that, contrary to general belief, memories of birth are available to certain individuals. Indeed, the curious thing about this case is that the baby had the ability not only to recall the events but also to be able to take in all the incoming external stimuli around him. How could he focus in such detail on the objects and people around him? It is generally believed that babies must learn to see things and recognize them as objects outside themselves. Here we have a newly born baby who seemed to recognize everything around him. Could it be that it is the newly born - but much older in actual lifetimes - Eidolon that recalled these images? It may take a few days for the Eidolon to forget how to process information and, as such, the birth memories are laid down fully.

It is reasonable to conclude that during the last few seconds of our previous life we will experience a full temporal lobe epileptic seizure, brought about by a cocktail of endogenous drugs that stimulate the brain into its final activities. A slowing down of time and a life review are then stimulated, and we start re-living that life again. However, as we emerge into our new life, the neurological echoes of the old are still reverberating around our brain. This can be shown by various experiments involving the attachment of electrodes to the stomach of a woman in late pregnancy. The brainwaves of the fetus are usually recorded as slow delta waves at a frequency of less than 3 cycles per second, but sometimes this regular pattern is interrupted by larger discharges similar to the spike recordings obtained from adults in an epileptic attack. As the baby approaches full term, these convulsive spikes become more frequent, until at birth they are almost continuous, as the child thrashes its way into the world. The implication seems to be that we are all born in something like epilepsy. If my theory is correct, then we die in a state of epileptic seizure and we are born in the same state.

The epileptic French writer Edmond de Goncourt was said to have described life as "a series of epileptic attacks, preceded and followed by a blank" (Bourget, cited in Lombroso, 1891, p. 342). In fact it seems more like "a blank, preceded and followed by an epileptic attack." Could it be that by living inside that blank we finally cheat the Ferryman? 


\section{References}

Bekenstein, J. D. (2003, August). Information in the holographic universe. Scientific American, pp. 58-65.

Bleuler, E. (1950). Dementia praecox or the group of schizophrenias (Zinkin, J., trans.). New York, NY: International Universities Press. (Original work published in German in 1911)

Bohm, D. (1980). Wholeness and the implicate order. London, England: Routledge and Kegan Paul.

Bohm, D., and Peat, F. D. (1987). Science, order, and creativity. New York, NY: Bantam.

Epictetus. (1998). Discourses. Book I (trans. By Dobbin, R. D.). Oxford, UK: Clarendon Press. (Original work published in $2^{\text {nd }}$ century)

Chew, G. F., Gell-Mann, M., and Rosenfeld, A. H. (1964, February). Strongly interacting particles. Scientific American, p. 74.

Deutsch, D. (1998). The fabric of reality: The science of parallel universes-and its implications. New York, NY: Penguin Books.

Everett, H. (1957). "Relative state" formulation of quantum mechanics. Review of Modern Physics, 29, 454-462.

Ferguson, M. (1973). The brain revolution: The frontiers of mind research. New York, NY: Taplinger.

Ferguson, M. (1982). Karl Pribram's changing reality. In Wilber, K. (ed.), The holographic paradigm (pp. 15-26). Boston, MA: Shambhala.

Friedman, J. R., Patel, V., Chen, W., Tolpygo, S. K., and Lukens, J. E. (2000). Quantum superposition of distinct macroscopic states. Nature, 406, 43-46.

Gabbard, G. O., and Twemlow, S. T. (1984). With the eyes of the mind: An empirical analysis of out-of-body states. New York, NY: Praeger.

Grof, S. (1976). Realms of the human unconscious. New York, NY: Dutton.

Hilgard, E. (1977). Divided consciousness: Multiple controls in human thought and action. New York, NY: Wiley.

Inglis, B. (1990). Coincidence: The language of destiny. London, England: Hutchinson.

James, W. (1950). The principles of psychology, Volume I. (New York, NY: Dover. (Original work published 1890)

Jaynes, J. (1976). The origin of consciousness in the breakdown of the bicameral mind. Boston, MA: Houghton Mifflin.

Kirshner, L. A. (1973). The mechanism of déjà vu. Diseases of the Nervous System, 34, 246-249.

Laibow, R. (1986). Birth recall: A clinical report. Pre- and Perinatal Psychology, 1, 78-81.

Lombroso, C. (1891). The man of genius. London, England: Walter Scott.

Maack, L. H., and Mullen, P. H. (1983). The doppelgänger, disintegration and death. Psychological Medicine, 13, 651-654.

Miller, R. J. (Ed.). (1992). The complete gospels: Annotated scholars version. San Francisco: Polebridge Press/HarperSanFrancisco.

Mollon, P. (1995). Multiple selves, multiple voices. New York, NY: Wiley.

MacDonald, N. (1960). Living with schizophrenia. Canadian Medical Association Journal, 82, 218-221.

Neppe, V. (1983a). The causes of déjà vu. Parapsychological Journal of South Africa, 4, 25-35.

Neppe, V. (1983b). The concept of déjà vu. Parapsychological Journal of South Africa, 4, $1-10$.

Neppe, V. (1983c). The incidence of déjà vu. Parapsychological Journal of South Africa, 4, 94-106.

Novak, P. (1997). The division of consciousness: The secret afterlife of the human psyche. Charlottesville, VA: Hampton Roads Publishing. 
Novak, P. (2002). Division of the self: Life after death and the binary soul doctrine. Journal of Near-Death Studies, 20, 143-189.

Novak, P. (2003). The lost secret of death: Our divided souls and the afterlife. Charlottesville, VA: Hampton Roads Publishing.

Osis, K., and Haraldsson, E. (1977). At the hour of death. New York, NY: Avon.

Paul, P. (1985). Some unseen power: The diary of a ghost hunter. London, England: Robert Hale.

Penfield, W., and Roberts, L. (1959). Speech and brain-mechanisms. Princeton, NJ: Princeton University Press.

Pribram, K. (1977). Some comments on the nature of the perceived universe. In Shaw, R., and Bransford, J. (eds.), Perceiving, acting, and knowing: Toward an ecological psychology (pp. 83-101). Hillsdale, NJ: Lawrence Erlbaum.

Puccetti, R. (1973). Brain bisection and personal identity. British Journal for the Philosophy of Science, 24, 339-355.

Rabban al-Tabari, A. I. (1928). Paradise of wisdom (Ziddiqui, M. Z., trans). Frankfurt, Germany: Institute for the History of Arabic-Islamic Science. (Original work published as Firdaus al-Hikma in the $9^{\text {th }}$ century.)

Rainer, J. D., Abdullah, S., and Altschuler, K. Z. (1970). Phenomenology of hallucinations in the deaf. In Keup, W. (ed.), Origin and mechanisms of hallucinations (pp. 449-456). New York, NY: Plenum Press.

Ramis, H. (Dir.). (1993). Groundhog day [Film]. Hollywood, CA: Columbia Pictures.

Rank, O. (1971). The double: A psychoanalytic study (trans. By Tucker, H.). Chapel Hill, NC: University of North Carolina Press. (Originally published as Der Doppelgänger: Eine psyshoanalytische Studie in German in 1925)

Saavedra-Aguilar, J. C., and Gómez-Jeria, J. S. (1989). A neurobiological model for neardeath experiences. Journal of Near-Death Studies, 7, 205-222.

Schrödinger, E. (1935). Die gegenwärtige Situation in der Quantenmechanik, Naturwissenschaften, 23, 807-812, 823-823, 844-849. [Trans. by Trimmer, J. D. (1980). Proceedings of the American Philosophical Society, 124, 323-38.]

Serdahely, W. J. (1987). The near-death experience: Is the presence always the higher self? Omega, 18, 129-134.

Sperry, R. W. (1976). Mental phenomena as causal determinants of brain function. In Globus, G. G., Maxwell, G., and Savodnik, I. (eds.), Consciousness and the brain: A scientific and philosophical inquiry (pp. 163-177). New York, NY: Plenum Press.

Tart, C. T. (1975). States of consciousness. New York, NY: Dutton.

Tegmark, M. (1998). The interpretation of quantum mechanics: Many worlds or many words? Fortschritte der Physik, 46, 855-862.

Wachowski, A., and Wachowski, L. (Dirs.) (1999). The matrix [Film]. Burbank, CA: Warner Brothers.

Watson, L. (1979). Lifetide: The biology of the unconscious. New York, NY: Simon and Schuster. 